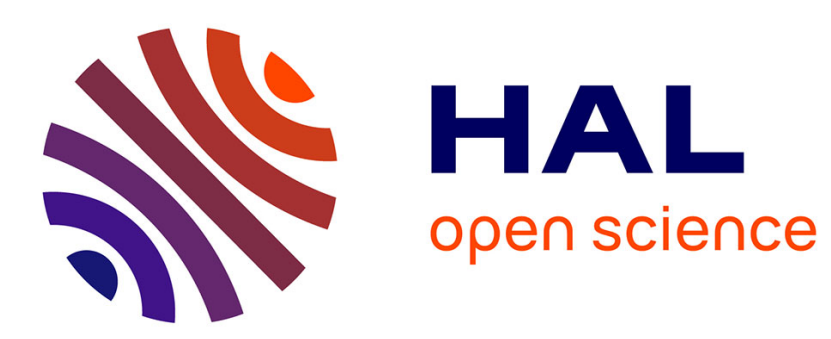

\title{
Characterization of hierarchical zeolites: Combining adsorption/intrusion, electron microscopy, diffraction and spectroscopic techniques
}

Izabel Medeiros-Costa, Catherine Laroche, Javier Pérez-Pellitero, Benoit Coasne

\section{To cite this version:}

Izabel Medeiros-Costa, Catherine Laroche, Javier Pérez-Pellitero, Benoit Coasne. Characterization of hierarchical zeolites: Combining adsorption/intrusion, electron microscopy, diffraction and spectroscopic techniques. Microporous and Mesoporous Materials, 2019, 287, pp.167-176. 10.1016/j.micromeso.2019.05.057 . hal-02328660

\section{HAL Id: hal-02328660 https://hal.science/hal-02328660}

Submitted on 5 Nov 2020

HAL is a multi-disciplinary open access archive for the deposit and dissemination of scientific research documents, whether they are published or not. The documents may come from teaching and research institutions in France or abroad, or from public or private research centers.
L'archive ouverte pluridisciplinaire HAL, est destinée au dépôt et à la diffusion de documents scientifiques de niveau recherche, publiés ou non, émanant des établissements d'enseignement et de recherche français ou étrangers, des laboratoires publics ou privés. 


\section{Characterization of hierarchical zeolites: Combining adsorption/intrusion,}

electron microscopy, diffraction and spectroscopic techniques

Izabel C. Medeiros-Costa ${ }^{\mathrm{a}}$, Catherine Laroche ${ }^{\mathrm{a}, *}$, Javier Pérez-Pellitero $^{\mathrm{a}, *}$, Benoit Coasne ${ }^{\mathrm{b}, *}$

${ }^{a}$ IFP Energies nouvelles, Rond-point de l'échangeur, BP3, 69360 Solaize, France

${ }^{\mathrm{b}}$ Univ. Grenoble Alpes, CNRS, LIPhy, F-38000 Grenoble, France

* Corresponding author. E-mail address: catherine.laroche@ifpen.fr (C. Laroche), javier.perez-pellitero@ifpen.fr (J. Perez-Pellitero), benoit.coasne@univ-grenoble-alpes.fr (B. Coasne). 
Abstract. Conventional and hierarchical faujasite zeolites, which are relevant to xylene separation by adsorption processes, are characterized using a broad set of complementary experimental techniques. In addition to a conventional faujasite zeolite, hierarchical faujasite zeolites consisting either of nanoparticle aggregates or of a layer-like zeolite are considered. For all samples, both the sodium and barium forms of these $\mathrm{X}$ zeolites are investigated. With the goal to predict and rationalize the efficiency of these materials for a given application, the fine characterization reported here aims at identifying key parameters such as their multiscale pore size distribution, pore connectivity/morphology, and external surface physical chemistry. $\mathrm{X}$-ray diffraction is first used to probe the different crystalline phases and domain sizes coexisting in each sample. Electron microscopy at different scales (scanning and transmission microscopies) is also used to determine the morphology of the different porosity domains as well as to investigate the core-shell structure of the samples. $\mathrm{N}_{2}$ adsorption and mercury intrusion are then combined to provide a consolidated multiscale pore size distribution of each sample.Furthermore, adsorption scanning curves are determined to analyze the topology/connectivity of the porosity domains. Finally, infrared spectroscopy and nuclear magnetic resonance are used to assess the chemistry of the samples with special focus on their external surface. The combination of these different techniques is found to provide a rich and detailed picture of these heterogeneous and multiscale solids that goes beyond standard routine characterization.

Keywords. Hierarchical zeolites, Adsorption and porosimetry, Infrared spectroscopy, Nuclear magnetic resonance, Electron microscopy, X-ray diffraction 


\section{Introduction}

Zeolites are porous crystalline aluminosilicates with an ordered porosity made up of micropores $(<2 \mathrm{~nm})$ that can accommodate a vast amount of molecules used in industry. These micropores confer to these materials a very large specific surface area and large specific porous volume that are responsible for their great adsorption capacity in separation, filtration, etc. [1,2]. Moreover, depending on the compensation mechanism of the negative charges induced by the silicon/aluminum substitution in these aluminosilicates, zeolites display either basic or acidic properties which can be used in many catalysis applications $[3,4]$. However, the ultraconfining microporous network in zeolites is generally associated with diffusional limitations which constitute a severe bottleneck for their industrial use. As an alternative to this problem, several strategies have been developed to increase micropore accessibility in zeolites. These approaches include a variety of synthesis methodologies able to generate a secondary porosity made up of mesopores $(2-50 \mathrm{~nm})$ or macropores $(>50 \mathrm{~nm})$ in zeolitic materials. These strategies lead to the formation of multiscale porous samples referred to as "hierarchical zeolites". The different approaches to the synthesis of such zeolites have been reviewed extensively in the literature [5-9]. The synthesis of nanozeolites, intergrowth processes, desilication/dealumination approaches, use of soft and hard templates, and structure rearrangement in the presence of surfactants are among the main methodologies that can be mentioned.

Hierarchical zeolites can be used to optimize productivity in many applications such as xylene separation; paraxylene molecules are separated from the different isomers (paraxylene, orthoxylene, and metaxylene) to be used as raw material for the production of plastics and textile fibers. In this application, separation is performed using faujasite zeolites whose properties are tuned by varying the nature of the compensating cation as well as the $\mathrm{Si} / \mathrm{Al}$ ratio to adjust the selectivity towards a given isomer [10]. Typically, BaX zeolite is paraselective, $\mathrm{NaX}$ zeolite is non-selective and $\mathrm{NaY}$ zeolite is meta-selective. However, despite its para-selectivity, the use of $\mathrm{BaX}$ is hindered by diffusion limitations as the size of the xylene molecules is close to that of the pore entrance. In this context, it should be emphasized that xylene separation in industry is performed using conventional zeolites and, to the best of our knowledge, the use of hierarchical zeolites has not yet been reported in the literature for this application. On the one hand, the use of hierarchical zeolites is expected to improve transport properties by the introduction of an additional porous network. On the other hand, when 
dealing with hierarchical zeolites, questions related to the impact of an increased external surface area arises. As pointed out by Bellat et al. [11], owing to its polar nature, the external surface is expected to be more selective towards the most polar isomer (metaxylene). As a result, using hierarchical faujasite zeolites for xylene separation requires finding an optimum in the trade-off between faster diffusion and efficient selectivity.

Designing a zeolite-based process with optimal diffusion/selectivity properties raises several underlying questions regarding the use and rational design of hierarchical zeolites. These questions include determining the optimal amount of mesoporous/macroporous volume and distribution within the sample. Such issues remain to be addressed as the design and engineering of hierarchical zeolites rely for the most part on trial and error strategies. To date, several types of hierarchical zeolites have been reported in the literature such as zeolite particles in which mesopores are added [12], nano-sized zeolites [13] and layers intergrowth [14-16]. However, such multiscale zeolitic structures are not necessarily optimal candidates for a specific application. Fine characterization of such zeolites is therefore required to determine robust structure-property relationships that would allow establishing in a second step rational synthetic routes.

In this paper, different hierarchical faujasite zeolites are characterized using a broad combination of techniques to better understand their surface and volume properties in an effort to rationalize and predict their subsequent use for xylene separation. Two types of hierarchical zeolites will be compared with conventional faujasite zeolite: nanoparticle aggregates (NA) and layer-like zeolite (LL). The NA zeolite consists of aggregates of small zeolite crystallites $(30-70 \mathrm{~nm})$; the mesoporosity between the crystals within the same aggregate provides an additional porosity scale (different samples of nanoparticle aggregates will be considered with the objective to vary the external surface area and meso/macroporous volume). The LL zeolite, which is formed by an array of faujasite zeolite layers, exhibits both inter-layer and intra-layer mesopores. Both the $\mathrm{NaX}$ and $\mathrm{BaX}$ forms for these different samples will be studied to gain insights into the effect of zeolite hierarchization. Fine characterization will allow the identification of key parameters such as multiscale pore size distribution and pore connectivity/morphology but also the amount and the chemistry of the external surface. With this goal, several experimental techniques are combined: $\mathrm{N}_{2}$ 
adsorption including scanning curve analysis, mercury intrusion, X-ray diffraction, electron microscopy, nuclear magnetic resonance (NMR) and infrared (IR) spectroscopies. An important goal in the present paper is to establish correlations between the external surface area as measured using adsorption-based techniques and its chemistry as probed using spectroscopy techniques. The remainder of this paper is organized as follows. In Section 2, the synthesis and preparation of the different hierarchical and conventional faujasite zeolites will be discussed. In this section, the different experimental methods are also briefly presented. In Section 3, the different characterization results obtained using adsorption/intrusion, X-ray diffraction, electron microscopy, IR spectroscopy and NMR are reported. In Section 4, we summarize our findings and provide some concluding remarks as well as perspectives for future work on the use of hierarchical zeolites for separation applications.

\section{Samples and Methods}

\subsection{Samples}

Two types of hierarchical faujasite zeolites were considered: nanoparticle aggregates (NA) and a layer-like zeolite (LL). The NA zeolites were obtained using a synthesis method adapted from the methodology proposed by Lechert et al. [17,18] to yield X faujasite spherical aggregates of a size about $0.8 \mu \mathrm{m}$. The synthesis of the LL zeolite was performed based on the organic-free approach using $\mathrm{LiCO}_{3}$ salt as proposed by Inayat et al. [19]. For comparison, a conventional $\mathrm{NaX}$ zeolite was also considered. This conventional zeolite is a commercial NaX Siliporite G5 obtained from Ceca-Arkema. All materials were obtained in their sodium form. To obtain the same samples in their barium form, the sodium zeolites were submitted to cation exchange. The exchange was carried out at $80^{\circ} \mathrm{C}$ for a period of $16 \mathrm{~h}$ using a $\mathrm{BaCl}_{2}$ solution at a concentration of $0.25 \mathrm{~mol} / \mathrm{L}$. At the end of the exchange period, the solution is cooled down and filtered under vacuum. The solid is then washed four times with $0.5 \mathrm{~L}$ of permuted water. After filtration, the solid is left at room temperature for about 1.5 days in order to evaporate the excess of water. Thereafter, the solid is taken to the oven and dried overnight at $100^{\circ} \mathrm{C}$. Elemental chemical analysis of all samples shows that they have a very similar chemical composition i.e. $\mathrm{Si} / \mathrm{Al}$ ratio $\sim 1.11+/-0.03$. 


\subsection{Experimental methods}

The porosity, pore size distribution in the micropore/mesopore range and specific surface area were determined for each sample from $\mathrm{N}_{2}$ adsorption at $77 \mathrm{~K}$ measured with a Micrometrics ASAP 2420. The $\mathrm{NaX}(\mathrm{BaX})$ samples were pretreated at $350^{\circ} \mathrm{C}\left(250^{\circ} \mathrm{C}\right)$ for $6 \mathrm{~h}$ under vacuum. The pore size distribution in the large mesopore/macropore range was assessed for each sample using mercury intrusion at room temperature measured on a Micromeritics IV autopore. The pre-treatment was carried out at $250^{\circ} \mathrm{C}$ for $2 \mathrm{~h}$ in a ventilated oven followed by $30 \mathrm{~min}$ in a desiccator.

X-ray diffraction was performed on a diffractometer Bruker AXS D4 Endeavor. The $\mathrm{X}$-ray source is an anticathode with copper-Ka radiation $(\lambda=1.5418 \AA)$. The data are collected using a Sol-XE energy dispersive detector. The morphology of the different zeolite samples was observed by means of scanning and transmission electron microscopies. Scanning electron microscopy (SEM) was performed in a low vacuum mode using a Nova NanoSem equipment. Transmission electron microscopy was performed using a JEM 2100F equipment. For both SEM/TEM techniques, the zeolite samples are first dispersed in ethanol. For the SEM analysis, the samples are impregnated with an epoxy resin and, then, subjected to ionic polishing. For TEM analysis, the sample preparation consists in the impregnation of the zeolite crystals in an epoxy resin which is then cut with a diamond blade. The lamina cuts have a thickness of about $70 \mathrm{~nm}$. These nanometric slices are then transferred to a copper grid which is covered with a holey carbon membrane.

The Fourier transform infrared spectroscopy (FTIR) was performed on a Vertex 702 (Bruker) spectrometer in the $\mathrm{OH}$ region $\left(3500 \mathrm{~cm}^{-1}-3800 \mathrm{~cm}^{-1}\right)$. The zeolite samples were pretreated at $400^{\circ} \mathrm{C}$ under vacuum for $10 \mathrm{~h}$ in the case of $\mathrm{NaX}$ zeolites and at $250^{\circ} \mathrm{C}$ under vacuum for $10 \mathrm{~h}$ in the case of $\mathrm{BaX}$ zeolites. The spectra were normalized per unit of sample mass. The zeolites were also analyzed by means of magic angle spinning (MAS) ${ }^{29} \mathrm{Si}$ nuclear magnetic resonance (NMR) on an Avance 400 spectrometer. The sequence High-power ${ }^{1} \mathrm{H}$ decoupling (HPDEC) was used. The rotation velocity of the samples was set to $8 \mathrm{kHz}$. The relaxation time was $20 \mathrm{~s}$ and the acquisition time of about $0.034 \mathrm{~s}$. In the case of ${ }^{1} \mathrm{H}$ NMR 
analysis, the samples were activated at $450^{\circ} \mathrm{C} / 10 \mathrm{~h}$ under vacuum and then analyzed by means of ${ }^{1} \mathrm{H}$ proton MAS NMR in a $4 \mathrm{~mm}$ MQMAS probe in a Bruker Avance 400 spectrometer (9.4 T). The ${ }^{1}$ H MAS NMR spectra were obtained using the spin echo sequence at a speed of $12 \mathrm{kHz}$. This sequence consists in applying a $\pi / 2$ pulse $(4.75 \mu \mathrm{s})$ followed by a $\pi$ pulse $(9.5$ $\mu \mathrm{s})$ at $53 \mathrm{kHz}$. The NMR spectra were normalized using the number of scans and sample mass, taking the conventional zeolite as reference.

\section{Results}

\subsection{Structure and morphology}

$\mathrm{X}$-ray diffraction is an important characterization tool for zeolites as it allows probing the zeolitic phases present in a given sample. Error! Reference source not found. shows the Xray diffractograms for the different $\mathrm{NaX}$ and $\mathrm{BaX}$ zeolites (both hierarchical and conventional zeolites are shown). As expected, the diffraction data for the hierarchical zeolites correspond to those for the $\mathrm{X}$ faujasite zeolite structure. The XRD data for the zeolite LL also reveals features corresponding to the minor presence of EMT zeolite [16] as can be inferred from a shoulder seen at low diffraction angles (marked with an asterisk in Fig. 1). In addition, traces of zeolite P can be observed for the LL sample (the arrows in Fig. 1 identify the most intense peaks of phase $\mathrm{P}$ in the XRD data). The EMT phase is also present in the NA-3 sample. An estimation of the amount of $\mathrm{NaX}$ phase in zeolites NA-3 and LL was made based on the diffraction pattern for zeolite NA-2. The sum of the amplitudes of the first four diffraction peaks for the NA-2 zeolite was used as a reference value for $\mathrm{NaX}$ zeolite. This value was compared to those obtained for the NA-3 and LL zeolites to determine their degree of crystallinity. The results indicate a $\mathrm{NaX}$ phase crystallization of at least $75 \%$ in NA-3 and $90 \%$ in LL. It is important to note that this result is only indicative of NaX phase crystallization since NA-2 zeolite was not synthesized under the same conditions as NA-3 and LL zeolites.

Fig. 1 also shows the X-ray diffractograms for the zeolites $\mathrm{BaX}$ as obtained after cation exchange. Comparison with the diffractogram for the conventional zeolite shows that the $\mathrm{BaX}$ faujasite structure is present in all hierarchical zeolites. Moreover, for the hierarchical zeolites, the amplitude of the corresponding peaks decreases and their width increases. The diffractograms for the zeolites NA-3 and LL display broader peaks followed by 
those for NA-2 and NA-1. While the EMT zeolite structure can be identified in the diffraction pattern for the $\mathrm{BaX}$ samples (see asterisk in Fig. 1), the $\mathrm{P}$ phase cannot be identified probably because of the broadness of the BaX peaks in the vicinity of those characteristic from the zeolite P. The typical crystallite size $C_{\mathrm{s}}$ for the different zeolites samples was estimated from the XRD data using Sherrer's equation:

$$
C_{\mathrm{s}}=\frac{k \lambda}{B(2 \theta) \cos \theta}
$$

where $k=0.9$ is the shape factor for spherical particles, $\lambda$ is the $\mathrm{X}$-ray wavelength, $B(2 \theta)$ is the peak width at half height, and $\theta$ is the diffraction angle. We found $C_{\mathrm{s}} \sim 180 \mathrm{~nm}$ for the conventional zeolite. $C_{\mathrm{s}} \sim 70 \mathrm{~nm}, 50 \mathrm{~nm}$, and $30 \mathrm{~nm}$ were found for the NA-1, NA-2 and NA3 zeolites, respectively while $C_{\mathrm{s}} \sim 30 \mathrm{~nm}$ was found for the LL zeolite. The crystallite sizes of the hierarchical zeolites are thus significantly smaller than that of the conventional zeolite. In addition, the crystallite size decreases from NA-1 to NA-3 while the LL zeolite presents a typical crystallite size similar to that of NA-3. It should be noted that the typical crystallite size does not necessarily correspond to the crystal sizes due to the presence of structure defects and aggregation (since a crystal can be made up of several crystallites which are separated by boundaries). For instance, the conventional $\mathrm{NaX}$ zeolite has well-defined crystals of a diameter $\sim 1.5 \mu \mathrm{m}$ as observed from electron microscopy while the crystallite size is about $0.18 \mu \mathrm{m}$.
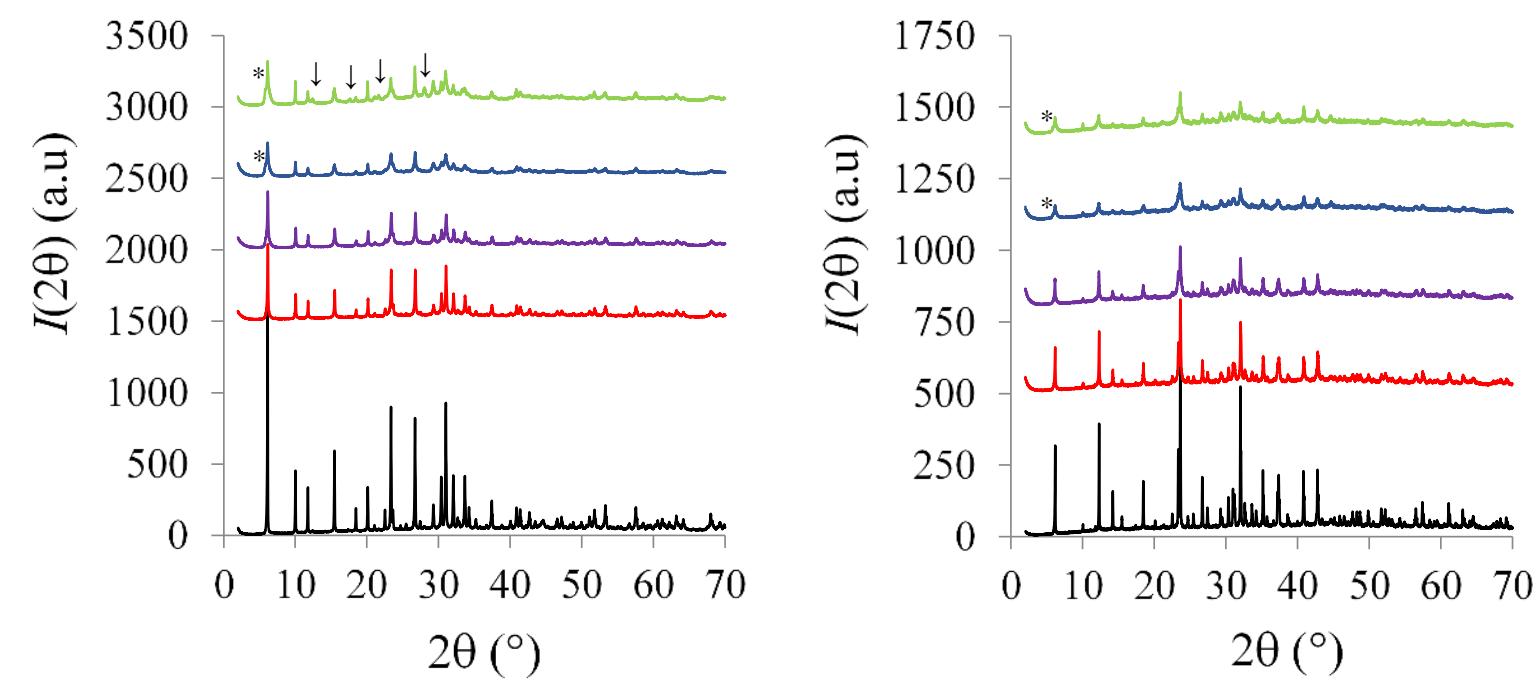

Fig. 1. (color online) X-ray diffractograms for $\mathrm{NaX}$ (left) and $\mathrm{BaX}$ (right) zeolites. Both conventional (black line) and hierarchical (color lines) zeolites are shown: NA-1 (red), NA-2 (purple), NA-3 (blue) and LL (green). The presence of zeolites P and EMT is indicated by the arrows and asterisks, respectively. 
The morphology of the conventional and hierarchical zeolites was studied using electron microscopy techniques such as SEM and TEM. In addition to the typical crystal diameter and arrangement, these techniques allow probing the presence of mesopores and macropores as well as their size and distribution. Fig. 2 shows typical SEM images for the different hierarchical samples. The NA samples exhibit an aggregated particle morphology with most particles having no well-defined shape (even though some of them are found to have a plate-like shape). The particles forming these aggregates appear larger and thicker for NA-1 than for the other NA zeolites. The particles in NA-1 are aggregated into sphere-like aggregates. The domain boundaries in the aggregates become less and less visible when moving from NA-1 to NA-3. The LL zeolite is made up of large spherical particles consisting of zeolite layers arranged in a house-of-cards like structure. Fig. 2 also shows for the same samples SEM images obtained on a cross-polished section. The NA-type hierachical zeolites can be divided in two sample types. On the one hand, NA-1 possesses a smaller external surface area and presents large dense microporous domains in each aggregate. For this sample, some mesopores and macropores seem to be radially distributed within the agglomerates while larger macropores $(D \sim 100-150 \mathrm{~nm})$ appear to be located in the center of the aggregates. On the other hand, NA-2 and NA-3 possess a larger external surface area, a smaller apparent average crystal/agglomerate size and less regular boundaries compared to NA-1. Nevertheless, some large macropores are also present in the center of the aggregates for these two samples. Finally, in the case of the LL zeolite, the macropores formed by the arrangement of zeolite layers appear to be connected to the external surface of the particles (the macropore entrances can be seen in more detail in Fig. S1 of the supplementary information). The internal structure of the LL zeolite, as observed in SEM images on a crosspolished section, suggests that the macropore entrances are not as deep as they appear to be in regular SEM images. Moreover, the crystalline particles for the LL zeolite seem to have dense edges with macropores located at the heart of the crystals (which can be up to $0.5 \mu \mathrm{m}$ long). 

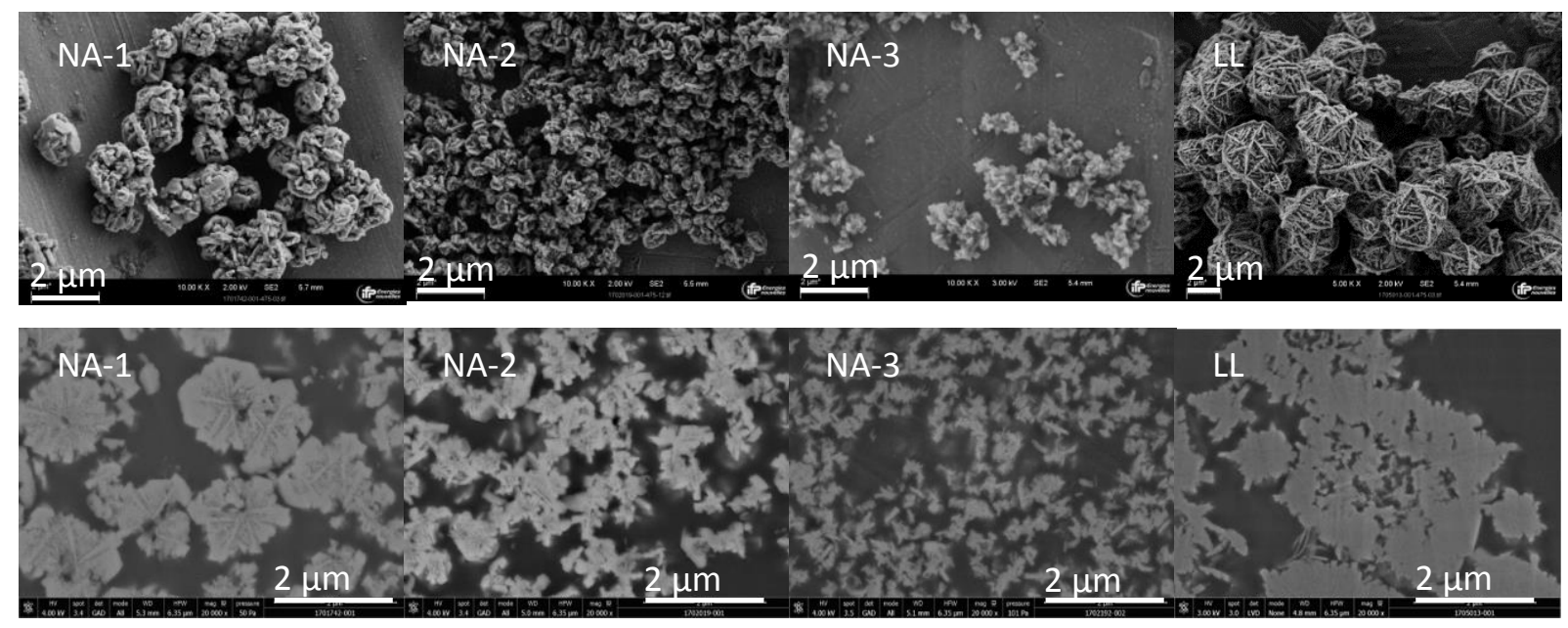

Fig. 2. SEM images of the hierarchical zeolites: (from left to right) NA-1, NA-2, NA-3 and LL. The top row corresponds to SEM images with a magnification size of about $2 \mu \mathrm{m}$. The bottom row, which shows the inner texture of the crystals, corresponds to images obtained by SEM-ionic polishing.

To identify the macropore connectivity, TEM images were obtained for the different hierarchical samples with a magnification allowing us to visualize the whole particles (Fig. 3). For the NA zeolites, the TEM pictures suggest the presence of channels connecting these macropores to the external surface. For the LL zeolite, connections between the external surface of the particles and the internal macropores could not be visualized; the shadows appearing in the TEM images are rather cutting defects generated upon sample preparation. The absence of connections between the internal macropores and the external surface for the LL zeolite will be confirmed below when discussing $\mathrm{N}_{2}$ adsorption (which suggests that cavitation occurs for this sample, being therefore consistent with the macropores being surrounded by a microporous matrix). 

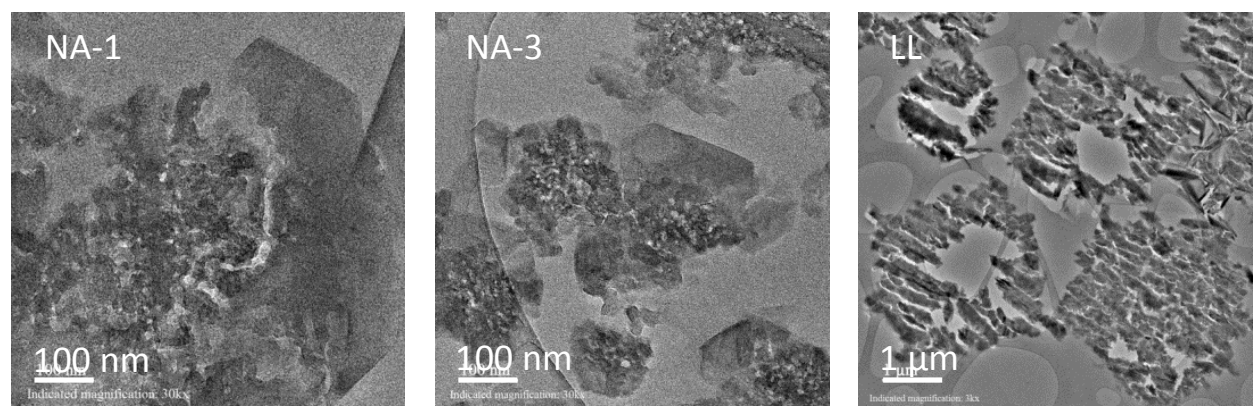

Fig. 3. TEM images of the hierarchical zeolites: (from left to right) NA-1, NA3 and LL.

The aggregated crystal form of the NA zeolites and the house-of-cards arrangement of the LL zeolite make it difficult to obtain an accurate crystal size distribution from electron microscopy images. While these morphologies do not allow determining the boundaries of the crystals inside a particle, the characteristic particle/aggregate size can be evaluated from electron microscopy techniques. For the NA-type hierarchical zeolites, the size of the aggregates was estimated from SEM images with a statistics over at least 100 units (Fig. 4). In the case of the NA-1 sample, most aggregates possess a size between 0.8 and $1.5 \mu \mathrm{m}$. For the samples NA-2 and NA-3, the histogram of aggregate sizes could not be determined but visual inspection of the SEM images suggest that NA-2 and NA-3 are made of smaller crystals than NA-1 (as can be observed in SEM images in Fig. 2). For the LL zeolite, the zeolite layers assemble to form roughly spherical particles (Fig. 2). The size distribution of such particles which is given in Fig. 4 mainly lies between 1.6 and $3.8 \mu \mathrm{m}$.
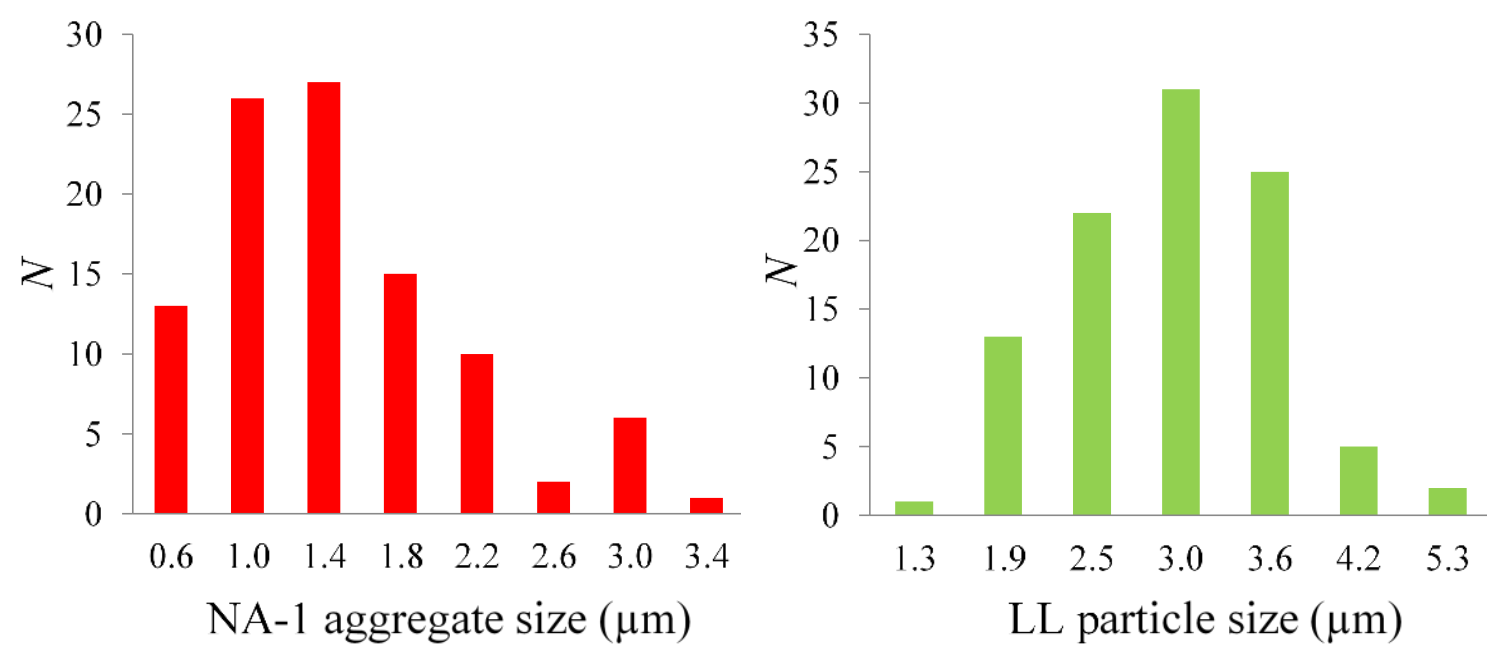

Fig. 4. (color online) Non-normalized particle size distribution for the NA-1 aggregates (left, red) and for the LL zeolite (right, green). 


\subsection{Textural parameters}

$\mathrm{N}_{2}$ adsorption isotherms were measured at $77 \mathrm{~K}$ for the different $\mathrm{NaX}$ and $\mathrm{BaX}$ zeolites (Fig. 5). The measured adsorption isotherms can be classified as a combination of type I (in the low pressure range) and type IV (in the intermediate and high pressure range) according to the IUPAC classification [20]. While type I is characteristic of microporous materials with significant adsorption in the micropores at low relative pressures, type IV is characteristic of mesoporous materials where capillary condensation occurs at higher relative pressures. The identification of a type IV adsorption isotherm for the different hierarchical zeolites is supported by the presence of capillary hysteresis loops. The $\mathrm{N}_{2}$ adsorption isotherms shown in Fig. 5 therefore confirm the hierarchical nature of these zeolites as they are representative of materials with both micropores and mesopores. The micropore volume for the different $\mathrm{BaX}$ and $\mathrm{NaX}$ samples can be estimated from the plateau in the adsorbed amount in the low pressure range (Fig. 5). Mainly due to the larger molecular weight of the zeolites in the $\mathrm{Ba}$ form, the micropore volume per mass unit of zeolite is smaller for the $\mathrm{BaX}$ zeolites than that for the $\mathrm{NaX}$ zeolites.. However, the significant specific volume decrease observed for the hierarchical zeolites also indicates some damage done to the zeolite structure during the cation exchange procedure which results in a loss of crystallinity.
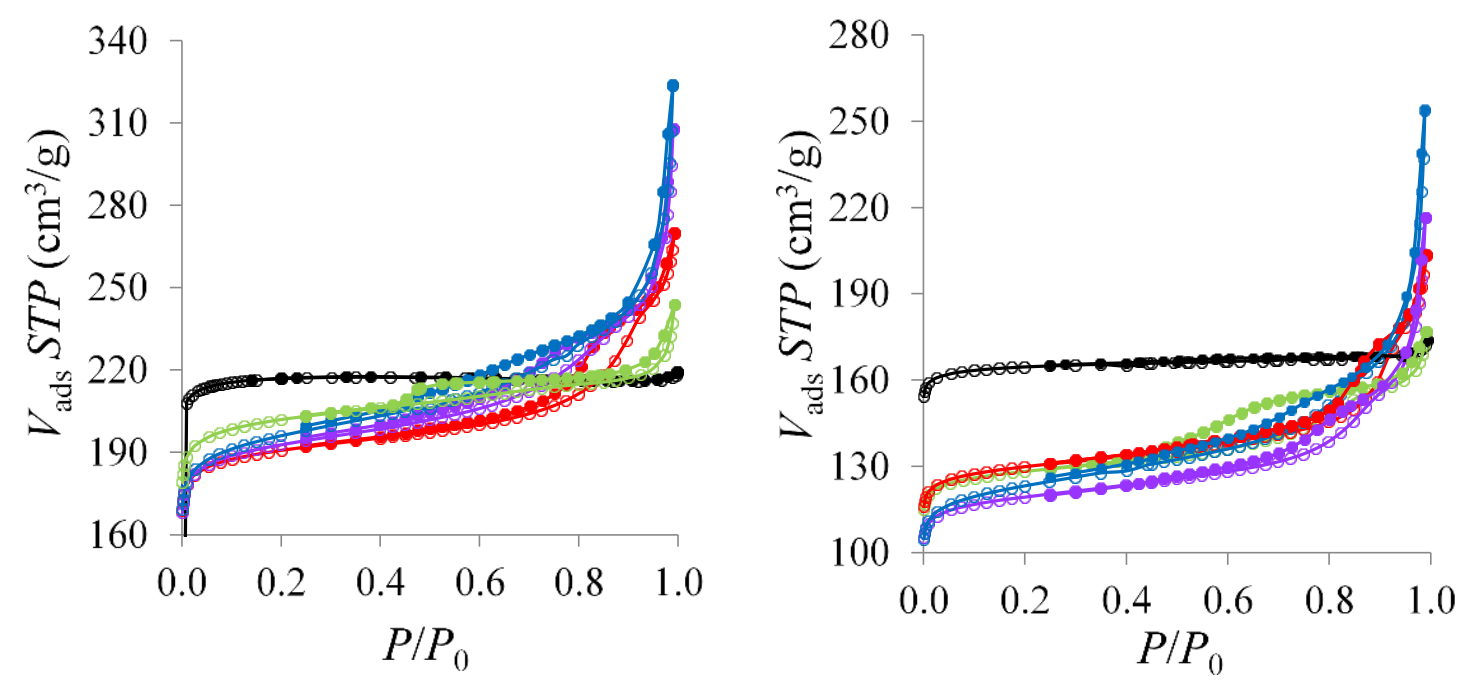

Fig. 5. (color online) $\mathrm{N}_{2}$ adsorption isotherms at $77 \mathrm{~K}$ of $\mathrm{NaX}$ (left) and $\mathrm{BaX}$ (right) conventional and hierarchical zeolites. Conventional zeolite (black) and hierarchical zeolites (color): NA-1 (red), NA-2 (purple), NA-3 (blue) and LL (green). $P / P_{0}$ is the $\mathrm{N}_{2}$ relative pressure $\left(P_{0}\right.$ is the bulk saturating vapor pressure at $\left.77 \mathrm{~K}\right)$ while the adsorbed amounts are given in $\mathrm{cm}^{3} \mathrm{STP}$ per $\mathrm{g}$ of zeolite. 
The textural and porosity data for the different $\mathrm{NaX}$ and $\mathrm{BaX}$ zeolites are presented in Table 1. For the $\mathrm{BaX}$ zeolites, an additional estimation of the different parameters was performed by assuming cationic exchange did not induce any structural damage. Despite its broad use for the characterization of porous media, the $t$-plot method has been reported to underestimate the micropore volume and overestimate the external surface area $[21,22]$. As an alternative to the $t$-plot method, it was decided to apply in this work another model known as direct identification. This model, which was proposed by Remy and Poncelet in 1995 [22], describes the adsorption in porous materials as the sum of the adsorption contributions in the micropores and at the external surface of a hierarchical zeolite. Consequently, this model seems well suited for the adsorbents under study in this work and allows identifying the textural parameters for hierarchical zeolites. Therefore, in the context of the present work, for each hierarchical zeolite, the $\mathrm{N}_{2}$ adsorption isotherm up to a relative pressure of $\sim 0.4 P_{0}$ was assumed to correspond to the sum of the two contributions occurring simultaneously but independently of each other: micropore filling and adsorption at the external surface area i.e. $V\left(P / P_{0}\right)=V_{\mu}\left(P / P_{0}\right)+V_{\text {ext }}\left(P / P_{0}\right)$. Micropore filling was modeled according to the Dubinin equation [23], $V_{\mu}\left(P / P_{0}\right)=V_{0} \exp \left[-R T / E \times \ln \left(P / P_{0}\right)\right]^{2}$ where $V_{0}$ is the total micropore volume, $R$ is the rare gas constant, $T$ is the temperature and $E$ is the characteristic adsorbate/solid energy. The adsorbed volume at the external surface area was estimated as the product of the external surface area $S_{\text {ext }}\left(\mathrm{in}^{2} / \mathrm{g}\right.$ ) and the adsorbed film thickness $t$ (in $\mathrm{nm}$ ) at a given partial pressure $\left(P / P_{0}\right), V_{\text {ext }}\left(P / P_{0}\right)=0.001 S_{\text {ext }} t\left(P / P_{0}\right)$. The latter was modeled according to the Harkins - Jura model and 0.001 is the conversion factor to obtain $V_{e x t}$ in $\mathrm{cm}^{3} / \mathrm{g}$. Each experimental $\mathrm{N}_{2}$ adsorption isotherm was fitted against $V\left(P / P_{0}\right)=V_{\mu}\left(P / P_{0}\right)+$ $V_{\text {ext }}\left(P / P_{0}\right)$ to determine the textural parameters given in Table 1 . While the adsorption isotherms in Fig. 5 are given in $\mathrm{cm}^{3} \mathrm{STP} / \mathrm{g}$, the textural parameters in Table 1 are given in $\mathrm{cm}^{3} / \mathrm{g}$. Moreover, the mesoporous volume given in Table 1 was obtained from the difference between the maximum adsorbed volume at $P / P_{0} \sim 1$ and the microporous volume. For both the $\mathrm{NaX}$ and $\mathrm{BaX}$ zeolites, as expected from their particle size distribution, both the external surface area and mesoporous volume increase for the NA type hierarchical zeolites according to the following order: NA-1 < NA-2 < NA-3. The LL zeolite presents an external surface area similar to that of NA-1 and the lowest mesoporous volume among all the hierarchical zeolites considered in this work. Overall, the hierarchical zeolites possess smaller microporous volumes than the conventional zeolite due to their lower degree of crystallinity. 


\section{Table 1}

Textural parameters calculated according to the direct identification model for the NaX and BaX conventional and hierarchical zeolites.

\begin{tabular}{|c|c|c|c|c|c|c|c|c|c|}
\hline \multirow[b]{3}{*}{ Conv } & \multicolumn{3}{|c|}{$\mathrm{NaX}$} & \multicolumn{6}{|c|}{$\mathrm{BaX}$} \\
\hline & \multirow{2}{*}{$\begin{array}{c}V_{\mu}\left(\mathrm{cm}^{3} / \mathrm{g}\right) \\
0.34\end{array}$} & \multirow{2}{*}{$\begin{array}{c}S_{\text {ext }}\left(\mathrm{m}^{2} / \mathrm{g}\right) \\
-\end{array}$} & \multirow{2}{*}{$\begin{array}{c}\mathrm{V}_{\text {meso }}\left(\mathrm{cm}^{3} / \mathrm{g}\right) \\
-\end{array}$} & \multicolumn{2}{|c|}{$\mathrm{V}_{\mu}\left(\mathrm{cm}^{3} / \mathrm{g}\right)$} & \multicolumn{2}{|c|}{$\mathrm{S}_{\mathrm{ext}}\left(\mathrm{m}^{2} / \mathrm{g}\right)$} & \multicolumn{2}{|c|}{$\mathrm{V}_{\text {meso }}\left(\mathrm{cm}^{3} / \mathrm{g}\right)$} \\
\hline & & & & 0.25 & $0.27 *$ & 11 & $0^{*}$ & 0.01 & $0^{*}$ \\
\hline NA-1 & 0.28 & 38 & 0.12 & 0.18 & $0.22 *$ & 43 & $30^{*}$ & 0.11 & $0.10^{*}$ \\
\hline NA-2 & 0.27 & 64 & 0.16 & 0.16 & $0.22 *$ & 48 & $51^{*}$ & 0.13 & $0.13^{*}$ \\
\hline NA-3 & 0.27 & 83 & 0.18 & 0.16 & $0.21 *$ & 68 & $66^{*}$ & 0.18 & $0.14^{*}$ \\
\hline LL & 0.29 & 45 & 0.05 & 0.18 & $0.23^{*}$ & 38 & $36^{*}$ & 0.08 & $0.04 *$ \\
\hline
\end{tabular}

* Theoretical values estimated using the molar mass of the zeolites before and after cation exchange and the textural data for the $\mathrm{NaX}$ zeolites.

The pore size distribution of a given multiscale porous medium such as hierarchical zeolites is often evaluated independently through two different techniques: probe gases adsorption (e.g. $\mathrm{N}_{2}$, Ar) is performed for the mesopore analysis while mercury intrusion is used for assessing macropores. Recently, Kenvin et al. [24] proposed the combination of these two techniques to obtain a consolidated multiscale pore size distribution (PSD). In this work, the PSD was evaluated through a similar unified approach which assesses the mesopore size distribution from the $\mathrm{N}_{2}$ adsorption data using the $\mathrm{BJH}$ model and the macropore size distribution from the mercury intrusion data using the Washburn-Laplace equation. The BJH model [25], which is based on the Kelvin equation, relates the change in the adsorbed/desorbed volume at a given pressure to the pore radius $r_{m}$ that fills/empties at the same pressure: $\ln P / P_{0}=-2 \gamma M / R T r_{k}$ where $\gamma$ is the gas/liquid surface tension and $M$ is the molar volume of the adsorbate. The pores are considered cylindrical and the Kelvin radius $r_{k}$ is taken equal to the mesopore radius $r_{m}$ minus the thickness of the adsorbed film $t$, i.e. $r_{k}=$ $r_{m}-t$. Mercury intrusion is a technique that allows probing large mesopores and macropores in porous media (typically, pore diameters from 4-10 nm up to microns). The intrusion pressure $P_{\mathrm{c}}$ is related to the pore diameter $D$ through the Washburn-Laplace equation: $P_{\mathrm{c}}=$ 
$-4 \gamma \cos \theta / D$ where $\gamma$ is the gas/liquid surface tension of mercury at room temperature and $\theta$ is the contact angle of the mercury meniscus. For most oxides, such as $\mathrm{SiO}_{2}$ and $\mathrm{Al}_{2} \mathrm{O}_{3}$, the contact angle $\theta$ is taken as $140^{\circ}[26]$.

Nitrogen desorption data are usually recommended to extract PSD for ordered materials using the $\mathrm{BJH}$ approach (because desorption occurs at thermodynamic equilibrium for regular pores) [27,28]. However, for disordered materials, the desorption branch rather describes narrower diameters (small pore entrances). The main limitation in obtaining pore size distribution derived from the desorption curve is related to the tensile strength effect (TSE) [29]. More in detail, this effect is associated to cavitation phenomena in the constricted pores and occurs at a relative pressure $\sim 0.42$ for $\mathrm{N}_{2}$ at $77 \mathrm{~K}$. Such a phenomenon leads to an artificial peak at $D_{\mathrm{TSE}} \sim 3.8 \mathrm{~nm}$ in the PSD determined from the desorption branch. Therefore, before determining the consolidated PSD, desorption and adsorption curves were evaluated according to the BJH method (Fig. S2 of the supplementary information). For the NA hierarchical zeolites, both the adsorption/desorption branches lead to a similar distribution of pore diameters except for the presence of a peak at $D \sim 4 \mathrm{~nm}$ in the case of the desorption branch for NA-1 and NA-2. The absence of this peak in the pore size distribution obtained from the adsorption branch suggests that it corresponds to an artefact that does not corresponds to a real pore diameter for these zeolites [30]. For the LL-type structure, the pore size distribution is significantly different between the $\mathrm{BJH}$ adsorption and desorption data. While the PSD obtained using BJH from the adsorption branch exhibits a broader pore size distribution, all porous volume in the PSD obtained using the desorption branch appears to correspond to pore diameters around diameters in the range $3.8-4 \mathrm{~nm}$. In this case, the occurrence of TSE effects is clearly identified. Based on the results above, the BJH technique was applied to the desorption branch for the NA samples and to the adsorption branch for the LL zeolite. 
The consolidated PSD are shown in Fig. 6 for the hierarchical $\mathrm{NaX}$ and $\mathrm{BaX}$ zeolites (both the data for the NA and LL zeolites are shown). Fig. 6 also shows the partial PSD as obtained in an independent way from nitrogen adsorption and mercury intrusion. Some overlap is observed between the mercury intrusion and nitrogen PSD, therefore indicating that both techniques provide the same information in the mesopore range. However, in the small mesopore range $(<4 \mathrm{~nm})$, the porosity in the different hierarchical samples cannot be probed by means of mercury intrusion. In contrast, mercury intrusion is the only technique able to explore the macropore range. In order to obtain the consolidated PSD, $\mathrm{d} V(D) / \mathrm{d} D$ (i.e. the pore volume $\mathrm{d} V(\mathrm{D})$ corresponding to pore diameters between $D$ and $D+\mathrm{d} D)$, the $\mathrm{N}_{2}$ adsorption and mercury intrusion data were combined according to the following relation:, $V(D)=$ $\max \left[V_{\mathrm{N} 2}(D), V_{\mathrm{Hg}}(D)\right]$ where $\max [\mathrm{a}, \mathrm{b}]=\mathrm{a}$ if $\mathrm{a}>\mathrm{b}$ and $\mathrm{b}$ otherwise. This rational criterion can be justified as follows. If a given technique ( $\mathrm{N}_{2}$ adsorption versus $\mathrm{Hg}$ intrusion) probes an existing pore population, it can reasonably be assumed that the corresponding pores exist i.e. are not a measurement artefact. As a result, we assume that the maximum pore volume observed for a given pore size is the most accurate measurement. The PSD for the NA zeolites in Fig. 6 provides evidence for both mesopores and macropores. The mesopores between 3.5 $30 \mathrm{~nm}$ correspond to the porosity between the crystals within the same agglomerate. The characteristic mesopore size, which is similar for the $\mathrm{NaX}$ and $\mathrm{BaX}$ zeolites, lies in the small mesopore range: $\sim 5 \mathrm{~nm}$ (NA-3 and LL), $\sim 8 \mathrm{~nm}$ (NA-2) and $\sim 13 \mathrm{~nm}$ (NA-3). The macropores (> $50 \mathrm{~nm}$ ) are mostly present between the aggregates but, as previously observed using SEM on cross-polished section (Fig. 2), some of these macropores are located in the center of the aggregates. For the LL zeolite, some macropores are also identified in the particle centers by means of electron microscopy (Fig. 2). However, such macropores are not observed using mercury intrusion as they are connected to the external surface area through pores that are too small to be intruded by mercury (possibly micropores). 

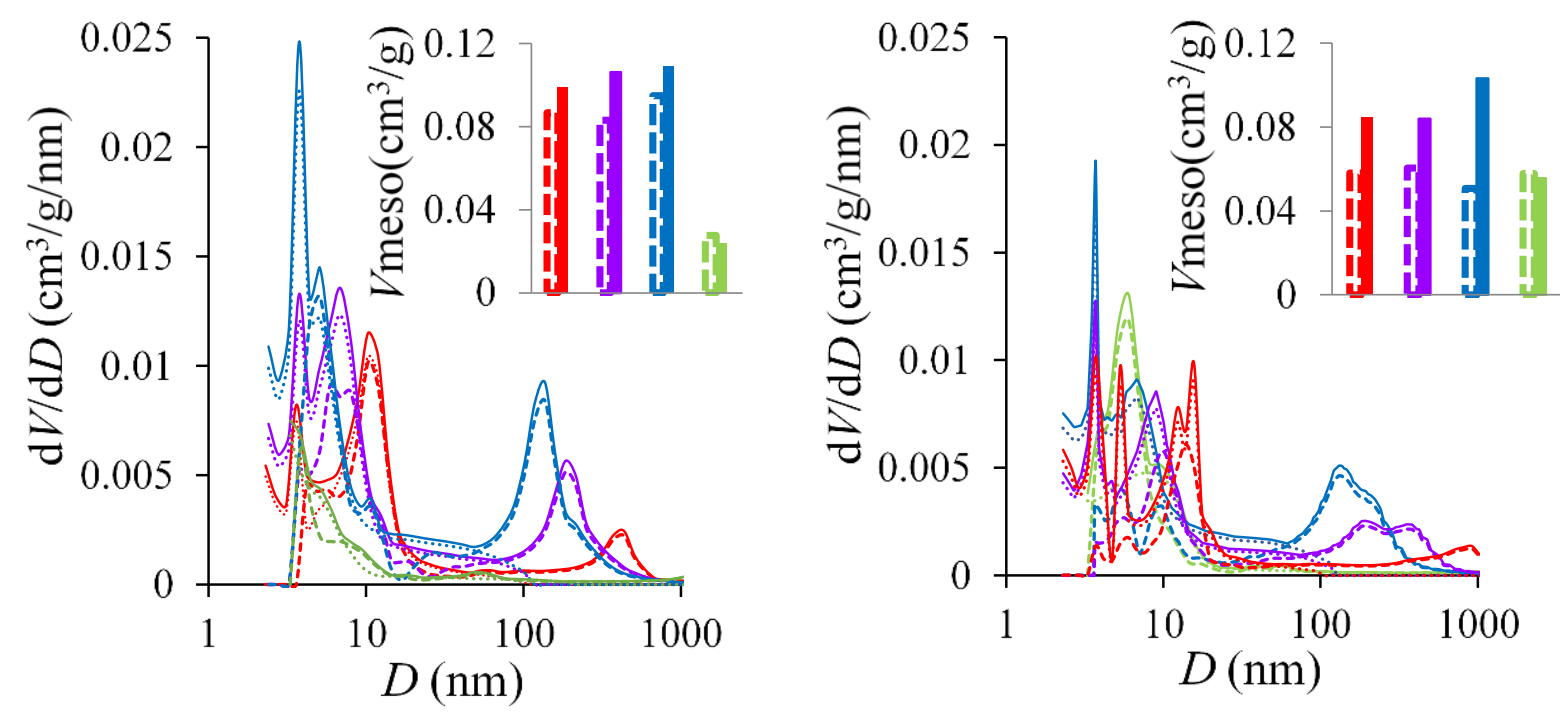

Fig. 6. (color online) Consolidated pore size distribution using $\mathrm{N}_{2}$ adsorption and $\mathrm{Hg}$ intrusion for the $\mathrm{NaX}$ (left) and $\mathrm{BaX}$ (right) zeolites. Both the conventional zeolite (black) and the hierarchical zeolites (color) are shown: NA-1 (red), NA-2 (purple), NA-3 (blue) and LL (green). The dotted lines correspond to $\mathrm{BJH}\left(\mathrm{N}_{2}\right.$ desorption data for $\mathrm{NA}$ zeolites and adsorption data for LL zeolite). The dashed lines correspond to mercury intrusion. The solid line corresponds to the consolidated distribution which was shifted upwards very slightly for better visualization. The inset shows the comparison between mercury intrusion (dashed contour line) and $\mathrm{N}_{2}$ desorption (solid contour line) volumes for pore diameters between 4 and $50 \mathrm{~nm}$.

\subsection{Domain connectivity}

Comparison between nitrogen adsorption and mercury intrusion also provides information regarding the accessibility of the mesopores [31,32]. Since mercury cannot access pores with a diameter below $4 \mathrm{~nm}$, comparison between the mesopore volume for pores between 4 and $50 \mathrm{~nm}$ as seen by $\mathrm{N}_{2}$ sorption and mercury intrusion allows identifying if these mesopores are accessible or isolated from the crystal external surface. In particular, such a comparison allows probing if the mesopores are separated from the external environment through constricting pores such as through micropores or small mesopores. As can be seen in the inset in Fig. 6 the volumes obtained for the $\mathrm{NaX}$ zeolites using both techniques are not identical but similar. More in detail, the mesopore volume seen by mercury intrusion for pore diameters between $4-50 \mathrm{~nm}$ correspond to $87 \%, 78 \%$ and $87 \%$ of the $\mathrm{N}_{2}$ mesopore volume for NA-1, NA-2 and NA-3, respectively. These values indicate that most mesopores are 
accessible from the external surface of the particles. For the BaX-NA zeolites, comparison between nitrogen adsorption and mercury intrusion indicates that the mesopores are less accessible than for the NaX-NA zeolites with only $50-72 \%$ of the $4-50 \mathrm{~nm}$ pores being accessible. As for the NaX-LL and BaX-LL zeolites, in contrary to macroporosity, all mesopores seem to be fully accessible from the external surface as the nitrogen and mercury mesopore volumes are very similar.

Hysteresis scanning curves were also measured to further probe the connectivity and accessibility between pore domains [28]. These scanning curves are obtained by partially filling (descending scanning curves) or emptying (ascending scanning curves) the pores of the material; Ascending (descending) scanning curves are then obtained by reversing upon desorption (adsorption) the direction of change in the pressure. In this work, for all NaX-NA hierarchical zeolites, three descending scans were made by starting the desorption from relative pressures of $P / P_{0} \sim 0.7,0.8$ and 0.9 . For the NaX-LL hierarchical zeolites, the scans were made from relatives pressures of $P / P_{0} \sim 0.6,0.8$ and 0.9 . In all cases, the complete adsorption isotherm - known as the boundary adsorption isotherm - was measured up to the relative pressure of $P / P_{0} \sim 1$. The maximum relative pressure for a given scan will be representative of the largest diameter of saturated pores [33]. As shown in Fig. 7, converging scanning curves - i.e. when the descending scanning curve converges and meets the boundary adsorption isotherm at its closure point - are observed for all NA hierarchical zeolites. For NA-1, the converging scanning curve, which indicates the presence of constricted pores, starts at $P / P_{0}=0.9$ (corresponding to pores of a diameter $\sim 15 \mathrm{~nm}$ ). However, the other scanning curves $\left(P / P_{0}=0.7\right.$ and 0.8$)$ that are representative of pores with a diameter up to $8.8 \mathrm{~nm}$ are reversible, which indicates the absence of pore blocking or cavitation effects for such pores. Therefore, one can assume that pores with a diameter smaller or equal to $8.8 \mathrm{~nm}$ are independent and accessible from the external surface of the particles. On the other hand, mesopores in the range between $8.8 \mathrm{~nm}$ and $15 \mathrm{~nm}$ desorb through pore blocking. In the case of the NA-2 and NA-3 zeolites, a very similar desorption behavior is observed. The descending scanning curve starting at $0.9 P / P_{0}$ for these two zeolites shows a desorption profile that matches the main desorption curve. This indicates that the corresponding mesopores behave independently so that they can be assumed to be fully accessible from the external surface. However, in both cases, mesopores of intermediate diameters $(8.8 \mathrm{~nm}$ for NaX-NA-2 and $9.9 \mathrm{~nm}$ for NaX-NA-3) seem to be constricted since converging-type descending scanning curves starting at $0.8 P / P_{0}$ are observed. For the NaX-LL zeolite, all 
descending scanning curves, including the boundary adsorption isotherm, close abruptly at the cavitation pressure. This confirms that the macropores identified in the particle centers by means of electron microscopy in the NaX-LL zeolite are isolated from the external surface of the particles through small pores (i.e. smaller than the critical diameter $D_{\mathrm{C}} \sim 3.8 \mathrm{~nm}$ for cavitation for $\mathrm{N}_{2}$ at $\left.77 \mathrm{~K}\right)[34,35]$.
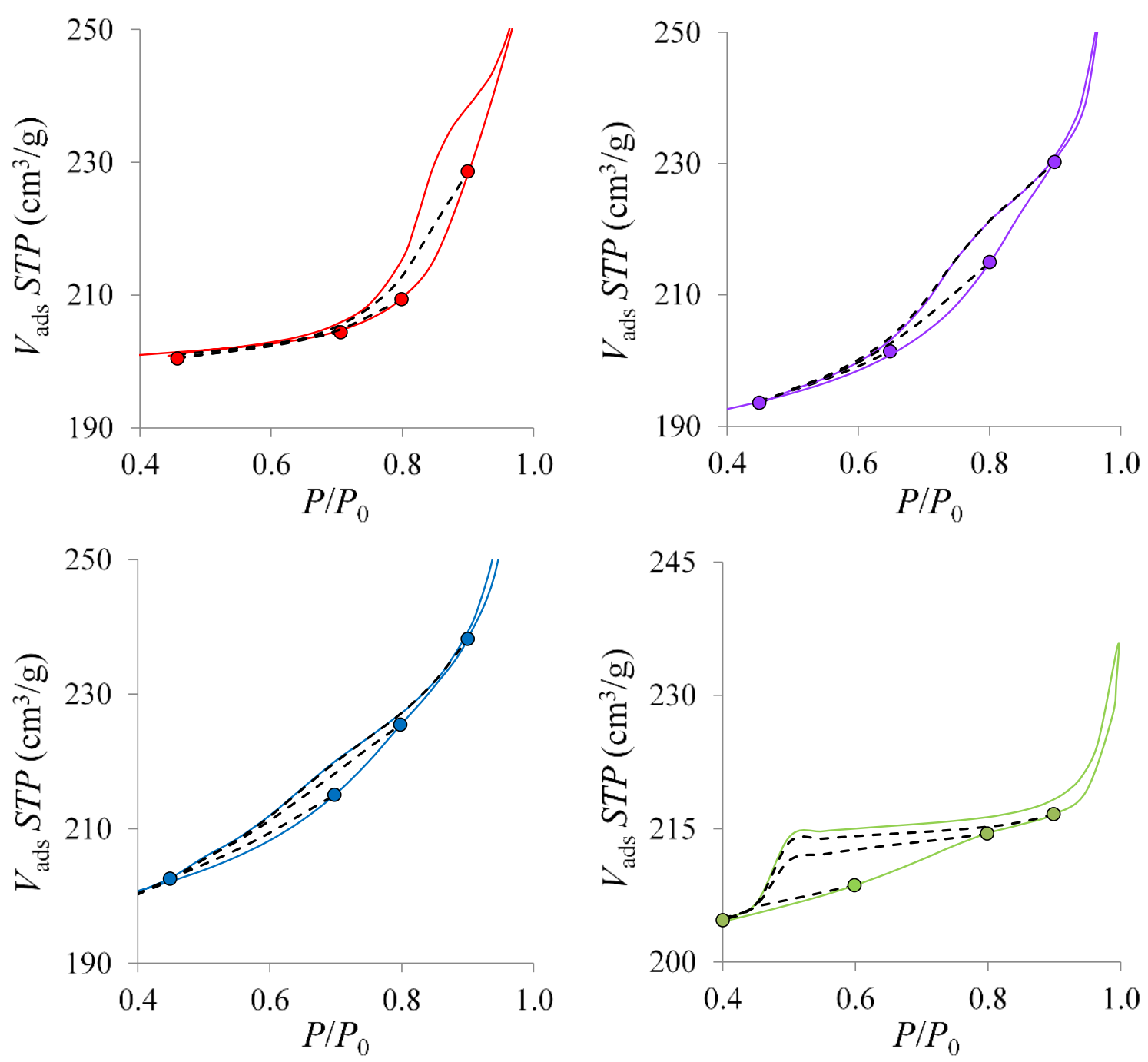

Fig. 7. (color online) Desorption scanning curves (dashed lines) and adsorption/desorption boundary adsorption isotherm (solid lines) for the NaX hierarchical zeolites: NA-1 (red), NA2 (purple), NA-3 (blue) and LL zeolite (green). The starting desorption pressures for NA zeolites are $P / P_{0} \sim 0.9,0.8$ and 0.7 . For the LL zeolite, the starting desorption pressures are $P / P_{0} \sim 0.9,0.8$ and 0.6 . 


\subsection{Surface chemistry}

IR spectroscopy and solid-state NMR techniques were used to investigate the surface chemistry of the different zeolite samples considered in this work. Fig. 8 shows the ${ }^{29} \mathrm{Si} \mathrm{NMR}$ spectra for the conventional and hierarchical $\mathrm{NaX}$ zeolites. The five peaks in these spectra correspond to $\mathrm{Si}$ atoms bonded to different numbers $n$ of $\mathrm{Al}$ atoms: $\mathrm{Si}(n \mathrm{Al})$ with $n=0,1,2,3$ and 4 [36]. The peaks $\mathrm{Si}(4 \mathrm{Al})$ and $\mathrm{Si}(3 \mathrm{Al})$ correspond to silicon atoms mainly present in the bulk zeolite crystal. In contrast, $\mathrm{Si}(2 \mathrm{Al})$ and $\mathrm{Si}(1 \mathrm{Al})$ peaks relate to silicon atoms which are more likely to be located at the crystal surface compared to $\mathrm{Si}(4 \mathrm{Al})$ and $\mathrm{Si}(3 \mathrm{Al})$. In addition, $\mathrm{Si}(2 \mathrm{Al})$ and $\mathrm{Si}(1 \mathrm{Al})$ peaks may include the contribution of surface/defect silanol groups such as $\mathrm{Si}(\mathrm{OH})_{2}$ and $\mathrm{Si}(\mathrm{OH})[37,38]$, respectively. An estimate of the amount of bulk Si atoms with respect to $\mathrm{Si}$ atoms that are more likely to be present at the surface can be obtained from the ratio between the sum of the amplitudes of $\mathrm{Si}(4 \mathrm{Al})$ and $\mathrm{Si}(3 \mathrm{Al})$ peaks and the sum of those of the $\mathrm{Si}(2 \mathrm{Al})$ and $\mathrm{Si}(1 \mathrm{Al})$ peaks. The following ratios were found for the different zeolites: conventional (5.8), NA-1 (5.9), NA-2 (4.1), NA-3 (4.0) and LL (4.5). As expected from their large crystal size, the conventional and NA-1 zeolites possess larger bulk contributions. As for the NA-2, NA-3 and LL zeolites, these results suggest that the LL zeolite possess a surface to volume ratio close to those of the NA samples with larger external surface area (NA-2/NA-3). However, it should be emphasized that this correlation remains only qualitative.

${ }^{1} \mathrm{H}$ NMR was used to gain insights into the $\mathrm{OH}$ groups present in the different zeolites considered in this work. The ${ }^{1} \mathrm{H}$ NMR spectra in Fig. 8 display three peaks which correspond to different $\mathrm{OH}$ groups (marked areas from left to right) [39]: (1) $\mathrm{OH}$ groups located in the supercages, (2) $\mathrm{SiOH}$ groups at the external surface or defects within the bulk zeolite crystals, and (3) $\mathrm{OH}$ groups interacting with cations in the supercages/external surface. According to the NMR data, the main contribution in both the conventional and hierarchical zeolites corresponds to $\mathrm{SiOH}$ groups at the external surface or defects. Furthermore, this contribution is much larger in the hierarchical zeolites than in the conventional zeolite. This result was expected since the hierarchical zeolites possess larger external surface areas than the 
conventional zeolite. However, by calculating the relative peak area for each of the $\mathrm{OH}$ groups contributions (see Fig. S3 in the supplementary information), we observe a nearly constant relative contribution of $\mathrm{SiOH}$ groups for the NA-type zeolites and a larger contribution for the LL zeolite. As for the amount of $\mathrm{OH}$ groups in the supercages, this contribution is much larger for the conventional zeolites than for the hierarchical zeolites. In this case, the relative contribution corresponding to this $\mathrm{OH}$ type in the hierarchical zeolites decreases as the external surface area increases (with a very small value for the LL zeolite). This suggests that the supercages are defective in these samples. Finally, the contribution corresponding to $\mathrm{OH}$ groups interacting with cations also increases upon increasing the external surface area of zeolites, therefore suggesting that some of these groups are located at the external surface. The LL zeolite, despite having a smaller external surface area than NA-3 zeolite, exhibits a relative amount of $\mathrm{OH}$ groups interacting with cations similar to zeolite NA-3.
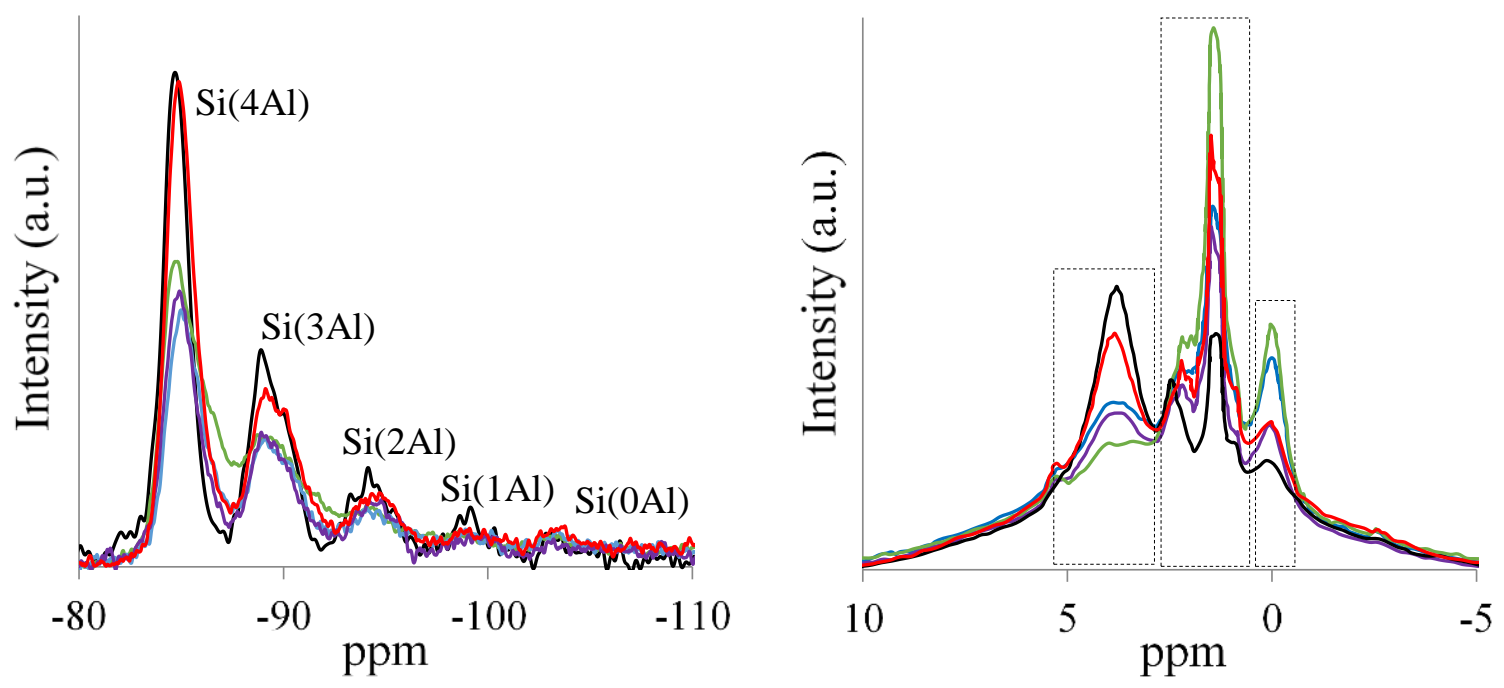

Fig. 8. (color online) ${ }^{29} \mathrm{Si}$ NMR (left) and ${ }^{1} \mathrm{H}$ NMR (right) analysis for NaX conventional and hierarchical zeolites. Conventional zeolite (black) and hierarchical zeolites (color): NA-1 (red), NA-2 (purple), NA-3 (blue) and LL (green). Each peak in the ${ }^{29} \mathrm{Si}$ NMR spectra corresponds to a number $n$ of alumina tetrahedrally-bonded to a central silicon $\operatorname{Si}(n \mathrm{Al})$. The areas delimited by the dashed lines in the ${ }^{1} \mathrm{H}$ NMR spectra indicate $\mathrm{OH}$ groups in different environments (see text). 
The external surface chemistry of the different zeolites was investigated using IR spectroscopy. The frequency range between 3500 and $4000 \mathrm{~cm}^{-1}$ was considered in detail as it corresponds to the vibration modes for silanol groups (either at the external surface or within the bulk of the zeolite crystals). In particular, the peak at $3740 \mathrm{~cm}^{-1}$ - marked with the dashed line in Fig. 9 - corresponds to the stretching of the $\mathrm{SiOH}$ groups located at the external surface of the crystals $[40,41]$. Since this peak indicates the presence of $\mathrm{OH}$ groups at the surface, its contribution is expected to be larger for hierarchical zeolites with a large external surface area. Other structural $\mathrm{OH}$ peaks can be identified in such IR spectra. (1) The small shoulder at $3720 \mathrm{~cm}^{-1}$ is assigned to $\mathrm{OH}$ groups at defective sites [42]. (2) The peak $\sim 3700 \mathrm{~cm}^{-1}$ results from the interaction of water molecules with cations; the fact that this peak has a large amplitude for the conventional zeolite can suggest incomplete water desorption upon pretreatment. (3) The peak at $\sim 3650 \mathrm{~cm}^{-1}$ corresponds to $\mathrm{OH}$ groups located in the supercages [43]; the large amplitude for this peak in the case of the conventional zeolite is consistent with the data obtained by means of ${ }^{1} \mathrm{H}$ NMR (see Fig. 8 and related discussion). (4) The peak at $3600 \mathrm{~cm}^{-1}$ corresponds to $\mathrm{OH}$ groups attached to extra-framework alumina debris (EFAL) [44]; This peak is observed for the conventional and hierarchical zeolites in their BaX form, therefore confirming that the ion exchange procedure leads to slight sample amorphization which generates EFAL.
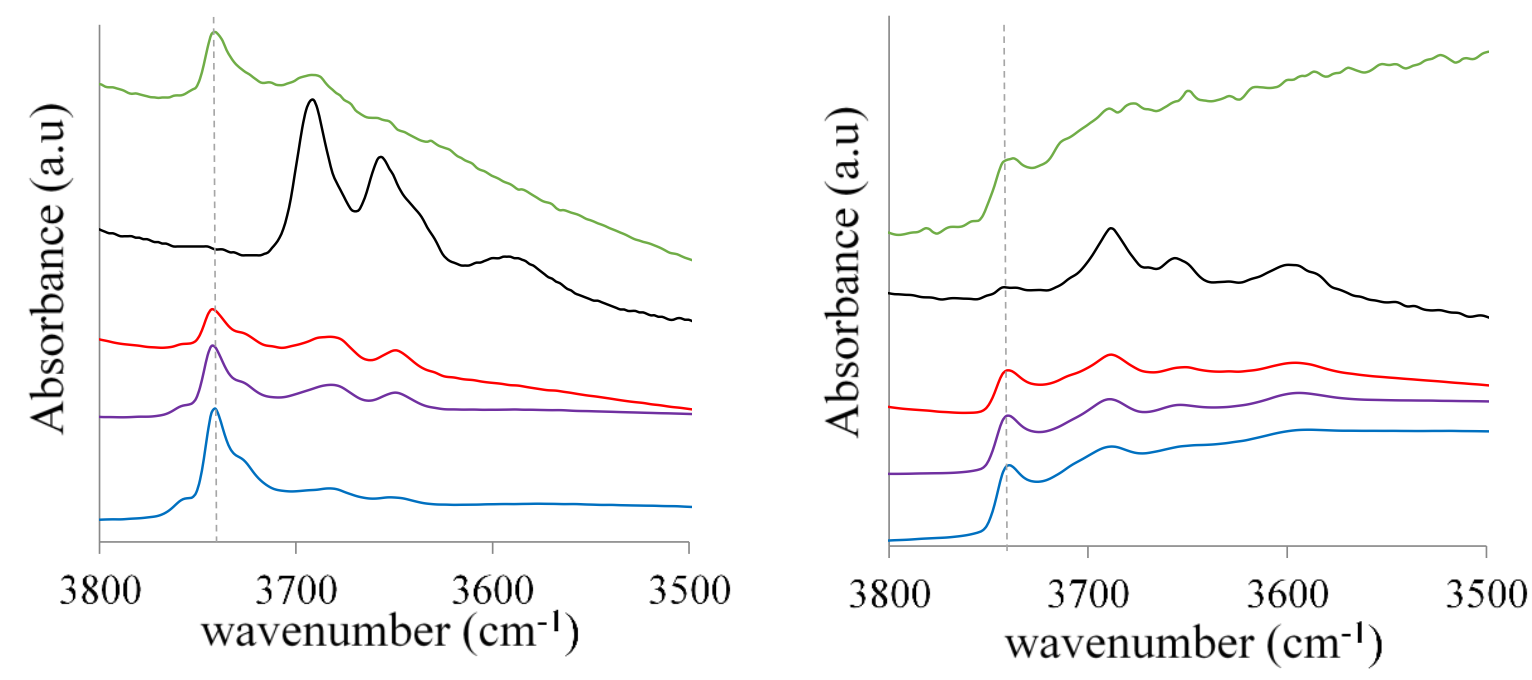

Fig. 9. (color online) Infrared spectra in the wavenumber range corresponding to the $\mathrm{OH}$ region for the $\mathrm{NaX}$ (left) and $\mathrm{BaX}$ (right) zeolites. Both the conventional (black) and hierarchical (color) zeolites are considered: NA-1 (red), NA-2 (purple), NA-3 (blue) and LL 
(green). The gray dashed lines indicate the band corresponding to silanol groups present at the external surface of the zeolites.

To estimate the amount of $\mathrm{OH}$ groups at the external surface of each zeolite sample, the amplitude of the IR peak at $\sim 3740 \mathrm{~cm}^{-1}$ was integrated. As can be seen in Fig. 10, a fairly linear correlation is observed between the external surface area of the zeolites and the area of this IR peak for the NA samples. This result indicates that, as expected, the amount of $\mathrm{OH}$ groups increases proportionally with the external surface of the zeolites. This implies that the NA hierarchical zeolites present the same $\mathrm{OH}$ group density at their external surface. While the LL zeolite in its $\mathrm{BaX}$ form quantitatively follows the same trend, its $\mathrm{NaX}$ form exhibits a large $\mathrm{OH}$ surface density. This result is consistent with the ${ }^{1} \mathrm{H}$ NMR data discussed above for this sample (see Fig. 8 and related discussion). While this important difference between the sodium and barium forms of the LL zeolite requires further investigation, we can anticipate that it must arises from the thermal treatment to which the samples are subjected in the ion exchange procedure. In the case of the conventional $\mathrm{BaX}$ zeolite, a small amount of $\mathrm{SiOH}$ groups could be identified due to the increase in its external surface area after ion exchange.
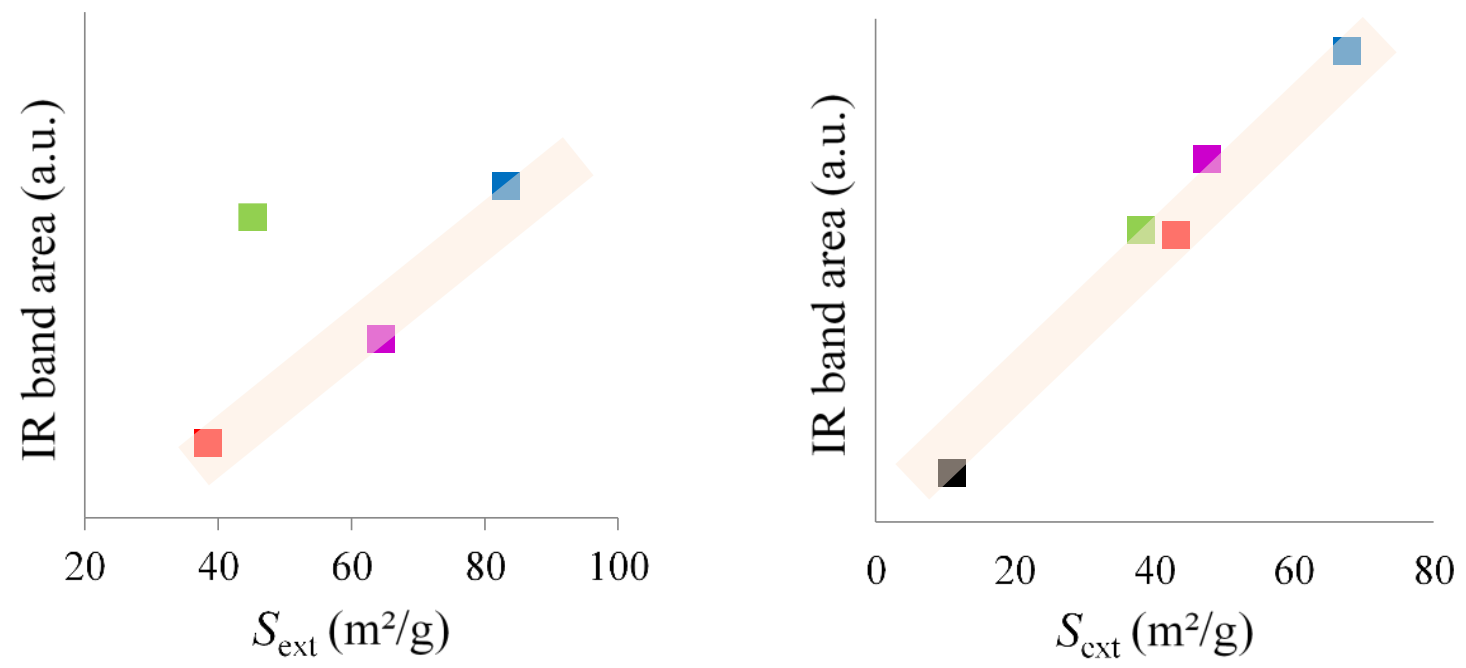

Fig. 10. (color online) Correlation between the peak area of the IR spectra for $\mathrm{SiOH}$ at the external surface (which scales linearly with the amount of $\mathrm{OH}$ groups) and the external surface area $S_{\text {ext }}$ as measured using $\mathrm{N}_{2}$ adsorption at $77 \mathrm{~K}$ : (left) $\mathrm{NaX}$ and (right) $\mathrm{BaX}$ hierarchical zeolites. Conventional zeolite (black), NA-1 (red), NA-2 (purple), NA-3 (blue) and LL (green). 


\section{Conclusion}

Our results show that characterization of complex heterogeneous and multiscale porous materials such as hierarchical adsorbents require the combination of complementary techniques. Such techniques, which include both invasive and non-invasive measurements, must allow probing the multiscale pore size distribution, pore connectivity/morphology, and external surface chemistry of the samples. In the present work, different conventional and hierarchical faujasite zeolites are characterized using a combination of X-ray diffraction, scanning and transmission electron microscopies, nitrogen adsorption-based techniques, mercury intrusion, infrared spectroscopy and nuclear magnetic resonance. The detailed multiscale picture obtained for the structure of these hierarchical materials is much richer than that inferred using standard characterization.

The different porosity domains as well as the external surface area of the hierarchical zeolites are assessed both from a qualitative and quantitative viewpoints. The comparison of $\mathrm{N}_{2}$ adsorption and mercury intrusion techniques is shown to provide very complementary information (unavailable if only one method is used) while allowing, at the same time, to estimate multiscale pore size distributions. The combination of these two techniques also provides information regarding pore accessibility/connectivity through the comparison between the pore volumes probed by means of $\mathrm{N}_{2}$ adsorption and mercury intrusion. Regarding the specific samples considered here, such adsorption/intrusion-based techniques show that most mesopores in hierarchical zeolites made of nanoparticle aggregates (NA) and layer-like zeolites (LL) are accessible through small pores having a diameter of at least $4 \mathrm{~nm}$. Electron microscopy at different scales (transmission and scanning techniques) is used to 
unravel the internal structure of the micron-sized particles composing the hierarchical zeolites; an important meso and macroporosity in the center of these crystalline particles is found to coexist with a dense microporous phase at the particle edge. The connectivity between these different pore domains is then investigated through the analysis of hysteresis scanning curves in the context of $\mathrm{N}_{2}$ adsorption measurements at low temperature. This analysis suggests that the mesopores/macropores are mostly accessible from the external surface of the zeolite (i.e. not encapsulated within the microporous phase). In the case of the LL zeolite, accessibility appears to occur through small pores so that desorption corresponds to cavitation. Finally, the surface chemistry of both the hierarchical and conventional zeolites was investigated by means of infrared spectroscopy and nuclear magnetic resonance techniques. Altogether, our results provide evidence for the presence of $\mathrm{SiOH}$ groups whose population scales with the external surface area of the zeolites. This suggests that, overall, the different zeolites considered here possess a very similar density of $\mathrm{SiOH}$ groups at their external surface.

The in-depth characterization proposed in this paper allows us to identify different important characteristics among the series of NA zeolites as well as between different hierarchical structures (NA and LL). Such differences may be important when predicting the performance of these zeolites for a given application. In the case of NA zeolites, the samples differ mostly in terms of meso/macropore size and volume as well as in terms of external surface area. Since small mesopores are an important limiting factor for the diffusion of adsorbing molecules, NA-1 is expected to perform better than the other zeolites owing to its large mesopores. However, for applications where a large mesopore volume and external surface area are required, NA-2 and NA-3 zeolites are expected to be optimal candidates. In addition, these two hierarchical zeolites present a smaller amount of dense microporous phase at the particle edge which should facilitate access to their microporosity. In general, the LL zeolite studied here is expected to present lower separation performance than the NA zeolites since it has a small external surface area and a low mesopore volume. Moreover, access to the mesopores/macropores in the LL zeolite mostly occurs through quite narrow pores. In the specific context of xylene separation using hierarchical faujasite zeolites, considering the size of the different xylene isomers, it is expected that diffusion will be significantly improved especially in the case of NA-2 and NA-3 zeolites. However, the possible detrimental impact of an increased external surface area on xylene selectivity needs to be investigated. 


\section{Acknowledgements}

We are happy to contribute with this paper to the special issue in honor of Pr. Joël Patarin. Among many crucial contributions to the field of zeolites and other related porous solids, Joël Patarin has made important achievements to help understand and develop their applications in adsorption, catalysis, etc.

\section{Appendix A. Supplementary Information}

Supplementary data associated with this article can be found, in the online version, at http://dx.doi.org/xxxx/yyyy.

\section{References}

[1] N. Kosinov, J. Gascon, F. Kapteijn, E.J.M. Hensen, J. Memb. Sci. 499 (2016) 65-79. doi:10.1016/j.memsci.2015.10.049.

[2] M.E. Davis, Ind. Eng. Chem. Res. 30 (1991) 1675-1683. doi:10.1021/ie00056a001.

[3] B.M. Weckhuysen, J. Yu, Chem. Soc. Rev. 44 (2015) 7022-7024. doi:10.1039/c5cs90100f.

[4] M. Dusselier, M.E. Davis, Chem. Rev. 118 (2018) 5265-5329. doi:10.1021/acs.chemrev.7b00738.

[5] S. Mintova, J.P. Gilson, V. Valtchev, Nanoscale. 5 (2013) 6693-6703. doi:10.1039/c3nr01629c.

[6] D.P. Serrano, J.M. Escola, P. Pizarro, Chem. Soc. Rev. 42 (2013) 4004-4035. doi:10.1039/c2cs35330j.

[7] L.H. Chen, X.Y. Li, J.C. Rooke, Y.H. Zhang, X.Y. Yang, Y. Tang, F.S. Xiao, B.L. Su, J. Mater. Chem. 22 (2012) 17381-17403. doi:10.1039/c2jm31957h.

[8] E. Koohsaryan, M. Anbia, Cuihua Xuebao/Chinese J. Catal. 37 (2016) 447-467. doi:10.1016/S1872-2067(15)61038-5.

[9] Z. Liu, Y. Hua, J. Wang, X. Dong, Q. Tian, Y. Han, Mater. Chem. Front. 1 (2017) 2195-2212. doi:10.1039/c7qm00168a.

[10] Y. Khabzina, C. Laroche, J. Perez-Pellitero, D. Farrusseng, Microporous Mesoporous Mater. 247 (2017) 52-59. doi:10.1016/j.micromeso.2017.03.026.

[11] J.P. Bellat, E. Pilverdier, M.H. Simonot-Grange, S. Jullian, Microporous Mater. 9 (1997) 213-220. doi:10.1016/S0927-6513(96)00108-3. 
[12] J. García-Martínez, M. Johnson, J. Valla, K. Li, J.Y. Ying, Catal. Sci. Technol. 2 (2012) 987-994. doi:10.1039/c2cy00309k.

[13] V.P. Valtchev, K.N. Bozhilov, J. Phys. Chem. B. 108 (2004) 15587-15598. doi:10.1021/jp048341c.

[14] D. Mehlhorn, A. Inayat, W. Schwieger, R. Valiullin, J. Kärger, ChemPhysChem. 15 (2014) 1681-1686. doi:10.1002/cphc.201301133.

[15] A. Inayat, I. Knoke, E. Spiecker, W. Schwieger, Angew. Chemie - Int. Ed. 51 (2012) 1962-1965. doi:10.1002/anie.201105738.

[16] M. Khaleel, A.J. Wagner, K.A. Mkhoyan, M. Tsapatsis, Angew. Chemie - Int. Ed. 53 (2014) 9456-9461. doi:10.1002/anie.201402024.

[17] H. Lechert, H. Kacirek, Zeolites. 11 (1991) 720-728. doi:10.1016/S01442449(05)80178-2.

[18] H. Lechert, H. Kacirek, Zeolites. 13 (1993) 192-200. doi:10.1016/S01442449(05)80277-5.

[19] A. Inayat, C. Schneider, W. Schwieger, Chem. Commun. 51 (2015) 279-281. doi:10.1039/c4cc07947g.

[20] K. S. W. Sing, D.H.Everett, R.A.W.Haul, L.Moscou; R.A.Pierotti, J.Rouquerol; T.Siemieniewska, Pure Appl. Chem. 57 (1985) 603-619. doi: 10.1515/iupac.57.0007

[21] A. Galarneau, F. Villemot, J. Rodriguez, F. Fajula, B. Coasne, Langmuir. 30 (2014) 13266-13274. doi:10.1021/la5026679.

[22] M.J. Remy, G. Poncelet, J. Phys. Chem. 99 (1995) 773-779. doi:10.1021/j100002a047.

[23] M.M. Dubinin, Chem. Rev. 60 (1960) 235-241. doi:10.1021/cr60204a006.

[24] J. Kenvin, J. Jagiello, S. Mitchell, J. Pérez-Ramírez, Langmuir. 31 (2015) 1242-1247. doi:10.1021/la504575s.

[25] E.P. Barrett, L.G. Joyner, P.P. Halenda, J. Am. Chem. Soc. 73 (1951) 373-380. doi:10.1021/ja01145a126.

[26] J.C. Groen, L. a a Peffer, J. Perez-Ramirez, Charact. Porous Solids Vi. 144 (2002) 91 98. doi:10.1016/S0167-2991(02)80224-5.

[27] B. Coasne, A. Galarneau, F. Di Renzo, R.J.M. Pellenq, Langmuir. 26 (2010) 1087210881. doi:10.1021/la100757b.

[28] B. Coasne, K.E. Gubbins, R.J.M. Pellenq, Adsorption. 11 (2005) 289-294. doi:10.1007/s10450-005-5939-y

[29] J.C. Groen, L.A.A. Peffer, J. Pérez-Ramírez, Microporous Mesoporous Mater. 60 (2003) 1-17. doi:10.1016/S1387-1811(03)00339-1. 
[30] J. Zečević, C.J. Gommes, H. Friedrich, P.E. Dejongh, K.P. Dejong, Angew. Chemie Int. Ed. 51 (2012) 4213-4217. doi:10.1002/anie.201200317.

[31] M. Milina, S. Mitchell, P. Crivelli, D. Cooke, J. Pérez-Ramírez, Nat. Commun. 5 (2014). doi:10.1038/ncomms4922.

[32] S. Mitchell, A.B. Pinar, J. Kenvin, P. Crivelli, J. Kärger, J. Pérez-Ramírez, Nat. Commun. 6 (2015). doi:10.1038/ncomms9633.

[33] J. Kenvin, S. Mitchell, M. Sterling, R. Warringham, T.C. Keller, P. Crivelli, J. Jagiello, J. Pérez-Ramírez, Adv. Funct. Mater. 26 (2016) 5621-5630. doi:10.1002/adfm.201601748.

[34] K.A. Cychosz, R. Guillet-Nicolas, J. García-Martínez, M. Thommes, Chem. Soc. Rev. 46 (2017) 389-414. doi:10.1039/c6cs00391e.

[35] C.J. Rasmussen, A. Vishnyakov, M. Thommes, B.M. Smarsly, F. Kleitz, A. V. Neimark, Langmuir. 26 (2010) 10147-10157. doi:10.1021/la100268q.

[36] E. Lippmaa, M. Mági, A. Samoson, M. Tarmak, G. Engelhardt, J. Am. Chem. Soc. 103 (1981) 4992-4996. doi:10.1021/ja00407a002.

[37] T.I. Korányi, J.B. Nagy, J. Phys. Chem. C. 111 (2007) 2520-2524. doi:10.1021/jp066578y.

[38] Z. Yan, D. Ma, J. Zhuang, X. Liu, X. Liu, X. Han, X. Bao, F. Chang, X. Lei, Z. Liu, J. Mol. Catal. Chem. 194 (2003) 153-167. doi:10.1016/S1381-1169(02)00531-

[39] M. Hunger, NMR Spectroscopy for the Characterization of Surface Acidity and Basicity, 2008. doi:10.1002/9783527610044.hetcat0059.

[40] K. Hadjiivanov, Identification and Characterization of Surface Hydroxyl Groups by Infrared Spectroscopy, 1st ed., Elsevier Inc., 2014. doi:10.1016/B978-0-12-8001271.00002-3.

[41] T. Kawai, K. Tsutsumi, J. Colloid Interface Sci. 212 (1999) 310-316. doi:10.1006/jcis.1999.6093.

[42] H.G. Karge, Microporous Mesoporous Mater. 22 (1998) 547-549. doi:10.1016/S13871811(98)80021-8.

[43] J.H. Lunsford, P.O. Fritz, J. Catal. 118 (1989) 85-98. doi:10.1016/00219517(89)90303-5.

[44] S. Khabtou, T. Chevreau, J.C. Lavalley, Microporous Mater. 3 (1994) 133-148. doi:10.1016/0927-6513(94)00015-8. 